\title{
A study to evaluate pregnancy with maternal heart disease: a prospective observational study at a tertiary care centre in India
}

\author{
Khushboo Goel, Sanjaykumar G. Tambe*
}

Department of Obstetrics and Gynecology, Byramjee Jeejeebhoy Government Medical College and Sassoon General Hospital, Pune, Maharashtra, India

Received: 30 January 2021

Revised: 08 March 2021

Accepted: 09 March 2021

\section{*Correspondence:}

Dr. Sanjaykumar G Tambe,

E-mail: sanjaykumartambe@gmail.com

Copyright: (C) the author(s), publisher and licensee Medip Academy. This is an open-access article distributed under the terms of the Creative Commons Attribution Non-Commercial License, which permits unrestricted non-commercial use, distribution, and reproduction in any medium, provided the original work is properly cited.

\section{ABSTRACT}

Background: Prevalence of heart disease in pregnancy vary from 0.3-3.5\%. Normal pregnancy is associated with physiological cardiovascular changes. These changes may unmask underlying cardiac disease in normal women and increase morbidity and mortality in women with heart disease. Heart disease in pregnancy is an important cause of maternal mortality in India. The aim of this study was to evaluate the maternal and neonatal outcome of pregnancy with heart disease.

Methods: A prospective observational study was conducted at Sassoon General Hospital, Pune, India. 75 patients who fulfilled the inclusion criteria were studied. Maternal and neonatal outcome were analyzed.

Results: Maternal heart disease was classified into congenital (36\%) and acquired (64\%). In acquired variety, rheumatic heart disease was most commonly seen. In congenital, ASD was most common. We divided the cases into two groups based on their NYHA status, low risk group had $74.67 \%$ patients and high risk group had $25.33 \%$ patients. The most common antenatal complication was PROM (41.3\%). There was statistically significant association between ICU admission and high-risk group. The most common neonatal complications were IUGR and prematurity. Maternal mortality rate in the study group was $6.6 \%$.

Conclusions: The perinatal outcome of heart disease in pregnancy is more dependent on the severity of symptoms rather than the duration and type of heart disease. Multidisciplinary evaluation is necessary. Suboptimal optimization of the heart condition in the antenatal period and delayed referral were the major risk factor for maternal mortality.

Keywords: Heart disease in pregnancy, Maternal mortality, Congestive cardiac failure, Neonatal outcome, Maternal outcome

\section{INTRODUCTION}

Maternal heart disease comprises $0.2-3 \%$ of pregnancies and is responsible for $10-25 \%$ of maternal deaths. In developing countries like India, rheumatic heart disease (RHD) still account for the majority of cases and mitral stenosis is the most common valvular lesion. Normal pregnancy and peripartum period are associated with physiological cardiovascular and circulatory changes. These changes may unmask underlying cardiac disease in normal women and increase morbidity and mortality in women with heart disease. ${ }^{1}$ With advances in pediatric cardiac surgery more women with congenital heart disease (CHD) are now surviving. Prevalence of heart disease in pregnancy vary from $0.3-3.5 \%{ }^{2,3}$ The circulatory changes in a pregnant patient with heart disease may lead to adverse events. Tertiary care centres may not replicate the exact prevalence of heart disease in pregnancy because they are referral centres in India. ${ }^{5}$ However, heart disease in pregnancy is an important cause of maternal mortality in India. ${ }^{5}$ It is estimated that heart disease accounts for $15 \%$ of pregnancy-related 
mortality. ${ }^{4}$ There is an increase in deaths due to heart disease and has re-emerged as one of the most common causes of maternal mortality. The incidence of cardiac disease is the same in different studies across the country, the etiology varies. ${ }^{5}$ Rheumatic heart disease is the predominant etiology while Mitral stenosis is the predominant heart lesion found in pregnancy. These observations agree with various Indian studies. ${ }^{6}$ Mortality is high if heart disease is complicated with infective endocarditis in pregnancy.

Therefore, every step should be taken to prevent this complication. Low birth weight and pre-term birth are the major neonatal complications in heart disease in pregnancy. The perinatal outcome is more dependent on the severity of symptoms during pregnancy rather than the duration and type of heart disease. ${ }^{3}$ These neonates also have an increased risk of congenital heart disease. Overall, the risk of such inheritance is quoted to be $3-5 \%$ compared to $1 \%$ risk in the general population. ${ }^{7}$ There is a gradual rise in the incidence of acquired cardiac disease in pregnancy all over the world. ${ }^{4}$ It may be due to delayed childbearing, increased medical disorders like hypertension, diabetes, and stress during pregnancy. The aim of this study was to evaluate the maternal and neonatal outcome of pregnancy with heart disease. This study provides local data and describes the burden of disease in a tertiary care hospital.

Aims and objectives were to study maternal heart disease for different etiologies and different types of lesions and to classify heart diseases in pregnancy in low risk and high risk group as per NYHA classification. Low risk: NYHA class I and II; High risk: NYHA class III and IV and to evaluate maternal and neonatal outcomes in pregnancy associated with maternal heart disease.

\section{METHODS}

This observational prospective study was conducted in a tertiary care teaching hospital in the department of Obstetrics and Gynaecology.

Various studies have shown the prevalence of heart disease in pregnancy is 0.2 to $3 \%$. The exact prevalence in our study area is not known hence we calculated the sample size for the prevalence of $0.2 \%$ and $3 \%$ while considering a confidence interval of $99 \%$. The sample size range obtained was 6 to 78. So for this study, sample size of 75 was taken. Samples were randomly selected who would fulfill the inclusion criteria.

\section{Inclusion criteria}

All pregnant women with congenital or acquired cardiac lesion or those with cardiac arrhythmias registered or referred to the hospital.

\section{Exclusion criteria}

All pregnant women with a confirmed diagnosis of heart disease who did not give consent to participate in the study, all pregnant women who were referred for Medical termination of pregnancy and all pregnant women who underwent voluntary Medical termination of pregnancy were excluded from the study.

\section{Methodology}

We studied 75 cases that fulfilled the inclusion criteria and delivered in the department of Obstetrics and Gynaecology from October, 2017 to March, 2019 at B. J. Government Medical College and Sassoon General Hospital, Pune, Maharashtra, India. General examination along with a detailed cardiovascular examination of the mothers was done. Physician, anaesthesiologist and cardiologist were involved along with the obstetrician in the management of these patients. They were closely monitored during and after the delivery till the discharge. Previous reports were analysed to evaluate maternal heart disease.

\section{RESULTS}

A total 75 patients with heart disease were analysed in this study excluding spontaneous abortion and termination of pregnancy before 28 weeks of gestation.

Table 1: Sociodemographic characteristics of the patients.

\begin{tabular}{|ll|}
\hline Patient characteristics & Number (\%) \\
\hline Age (years) & \\
\hline $16-20$ & $12(16)$ \\
\hline $21-25$ & $45(60)$ \\
\hline $26-30$ & $12(16)$ \\
\hline $31-35$ & $4(5.33)$ \\
\hline $36-40$ & $2(2.66)$ \\
\hline Gestational age (weeks) & $23(31)$ \\
\hline Full term (>37 weeks) & $52(69)$ \\
\hline Preterm (<37weeks) & \\
\hline Parity & $26(34.6)$ \\
\hline Primigravida & $49(65.3)$ \\
\hline Multigravida & \\
\hline ANC Registration & $60(80)$ \\
\hline Registered (more than 3 ANC visits) & $15(20)$ \\
\hline $\begin{array}{l}\text { Unregistered (less than or equal to 3 } \\
\text { ANC visits) }\end{array}$ \\
\hline
\end{tabular}

The previous history of any cardiac surgery, ECG changes, 2D ECHO report etc. were documented. Infective endocarditis prophylaxis was administered to all patients. 
Table 2: Etiological classification of the patients with heart disease.

\begin{tabular}{|ll|}
\hline Etiology & $\begin{array}{l}\text { Number of cases } \\
(\%)\end{array}$ \\
\hline Congenital & $27(36)$ \\
\hline Atrial septal defect (ASD) & $12(44.4)$ \\
\hline Ventricular septal defect & $5(18.5)$ \\
\hline Patent ductus arteriosus & $4(14.8)$ \\
\hline Tetralogy of Fallot & $2(7.4)$ \\
\hline Coarctation of aorta & $1(3.7)$ \\
\hline $\begin{array}{l}\text { Acquired ( Rheumatic valvular } \\
\text { heart disease RVHD) }\end{array}$ & $48(64)$ \\
\hline Mitral stenosis & $14(29.1)$ \\
\hline Mild MR & $10(20.8)$ \\
\hline Moderate - severe (MR) & $14(29.1)$ \\
\hline Pulmonary artery hypertension & $10(20.8)$ \\
\hline Aortic stenosis & $2(4.16)$ \\
\hline Aortic regurgitation & $3(6.25)$ \\
\hline Pulmonary stenosis & $3(6.25)$ \\
\hline Pulmonary regurgitation & $1(2.08)$ \\
\hline
\end{tabular}

Many patients had a combination of the above mentioned lesions

Table 3: Distribution of the cases.

\begin{tabular}{|ll|}
\hline Classification & $\begin{array}{l}\text { Number of } \\
\text { cases }(\%)\end{array}$ \\
\hline WHO classification & $18(24)$ \\
\hline Class I & $28(37.33)$ \\
\hline Class II & $12(16)$ \\
\hline Class III & $17(22.67)$ \\
\hline Class IV & \\
\hline NYHA grading & $9(12)$ \\
\hline NYHA I & $47(62.67)$ \\
\hline NYHA II & $13(17.33)$ \\
\hline NYHA III & $6(8)$ \\
\hline NYHA IV & \\
\hline CARPREG score & $32(42.67)$ \\
\hline 0 & $29(38.67)$ \\
\hline 1 & $14(18.67)$ \\
\hline$>1$ & \\
\hline Left ventricular functional status & $0(0.00)$ \\
\hline Hyperdynamic (LVEF > 70\%) & $69(92)$ \\
\hline Normal (LVEF 50-70\%) & $2(2.67)$ \\
\hline Mild dysfunction (LVEF 40-49\%) & $3(4)$ \\
\hline $\begin{array}{l}\text { Moderate dysfunction (LVEF 30- } \\
\text { 39\%) }\end{array}$ & $1(1.33)$ \\
\hline Severe dysfunction (LVEF < 30\%) & \\
\hline
\end{tabular}

Mode of delivery and maternal complications were documented. Newborn's assessment was done for their APGAR score, the need of resuscitation, presence of congenital heart disease/ other congenital anomalies, IUGR status, need and cause of NICU admission. Postdelivery $2 \mathrm{D}$ echo was done, whenever necessary. The data obtained was recorded on a Microsoft Excel spreadsheet and analysed using SPSS version 16. 45 (60\%) patients in the study groups belonged to the age group $21-25$ years with minimum age being 18 years and maximum being 40 years. $46(65.3 \%)$ patients were multigravida and $26(34.6 \%)$ patients were primigravida. $52(69 \%)$ patients were preterm. $15(20 \%)$ patients had less than 3 antenatal visits (Table 1). 27 (36\%) patients in the study group had congenital heart disease while $48(64 \%)$ patients had acquired (rheumatic in origin) heart disease. In congenital lesions, ASD was the most common heart lesion, present in $44 \%$ of patients with congenital heart disease. In RVHD, mitral stenosis was the most common lesion, present in $30 \%$ patients followed by mitral regurgitation in another $30 \%$ patients. (Table 2).

As per WHO classification $28(37.3 \%)$ of our patients belonged to WHO class II, $18(24 \%)$ to WHO class I, 17 (22.6\%) to class IV and $12(16 \%)$ to class III. As per CARPREG risk score, 32(42.67\%) had score 0,29 $(38.67 \%)$ had score 1 and 14 (18. 67\%) had score $>1$. Risk estimation of cardiovascular maternal complications is $5 \%, 27 \%$ and $75 \%$ for the score of 0,1 and $>1$ respectively. As per NYHA grading, most of our patient i.e. $62.7 \%$ belonged to NYHA grade II followed by $17.33 \%$ to NYHA III, $12 \%$ to NYHA I and $8 \%$ to NYHA IV. When we classified as per the grade of LV dysfunction, $92 \%$ had normal LV function, $3 \%$ mild dysfunction, $4 \%$ moderate dysfunction and $1 \%$ severe dysfunction. (Table 3).

We divided the cases into two groups based on their NYHA status $74.67 \%$ patients belonged to the low risk group and $19(25.33 \%)$ belonged to the high risk group. (Table 4).

The most common antenatal complication was premature rupture of membranes $(41.3 \%)$ followed by IUGR $(30.67 \%)$. On application chi square test, high risk group was significantly associated with IUGR. (Pearson ChiSquare 12.634 and $\mathrm{p}$ 0.00379).Preterm labour was found in $52.6 \%$ of high risk and $19.6 \%$ of low risk patient which was statistically significant. (Table 5)

Out of 56 low risk patients, $43(76.79 \%)$ delivered vaginally while $8(14.2 \%)$ had a cesarean delivery and 5 $(8.9 \%)$ had assisted vaginal delivery. Among the 18 high risk patients, $5(27.78 \%)$ delivered vaginally while 8 $(43.4 \%)$ required cesarean delivery and $4(22.22 \%)$ had an instrumental delivery. One high risk patient died before delivery.

Table 4: Risk categorization according to NYHA status.

\begin{tabular}{|ll|}
\hline Risk using NYHA grade & Number of cases (\%) \\
\hline Low (NYHA I+II) & $56(74.67)$ \\
\hline High (NYHA III+IV) & $19(25.33)$ \\
\hline
\end{tabular}


Table 5: Maternal complications among study groups during antenatal period.

\begin{tabular}{|c|c|c|}
\hline \multirow{2}{*}{$\begin{array}{l}\text { Antenatal } \\
\text { complication }\end{array}$} & $\begin{array}{l}\text { Low risk } \\
\text { group } \\
(n=56)\end{array}$ & $\begin{array}{l}\text { High risk } \\
\text { group }(n=19)\end{array}$ \\
\hline & $\begin{array}{l}\text { Number } \\
\text { of cases } \\
(\%)\end{array}$ & $\begin{array}{l}\text { Number of } \\
\text { cases }(\%)\end{array}$ \\
\hline Anemia & $4(7.14)$ & $5(26.34)$ \\
\hline $\begin{array}{l}\text { Intrauterine growth } \\
\text { restriction }\end{array}$ & $9(16.07)$ & $14(73.6)$ \\
\hline Preterm labour & $2(3.57)$ & $10(17.8)$ \\
\hline Preclampsia & $5(8.92)$ & $5(26.3)$ \\
\hline $\begin{array}{l}\text { Premature rupture of } \\
\text { membranes }\end{array}$ & $18(32.14)$ & $13(68.4)$ \\
\hline Intrauterine death & $1(1.78)$ & $2(10.5)$ \\
\hline $\begin{array}{l}\text { Preterm premature } \\
\text { rupture of } \\
\text { membranes }\end{array}$ & $2(3.75)$ & $6(31.57)$ \\
\hline Malpresentation & $1(1.78)$ & $0(0.00)$ \\
\hline Placenta previa & $1(1.78)$ & $0(0.00)$ \\
\hline Hypothyroidism & $2(2.75)$ & $0(0.00)$ \\
\hline Oligohydramnios & $1(1.78)$ & $0(0.00)$ \\
\hline Previous LSCS & $6(10.71)$ & $6(31.57)$ \\
\hline Infections & $1(1.78)$ & $1(5.26)$ \\
\hline Thrombocytopenia & $1(1.78)$ & $0(0.00)$ \\
\hline Multifetal gestation & $1(1.78)$ & $0(0.00)$ \\
\hline
\end{tabular}

Postpartum complications were seen more commonly in high risk group. The most common complication in the low risk group was post partum haemorrhage followed by congestive cardiac failure, acute hypoxia and anemia. In the high risk group, the most common complication was congestive cardiac failure and acute pulmonary edema. (Table 6).
$6(10.71 \%)$ patients from low risk group needed ICU (intensive care unit) stay following delivery while 13 (68.42\%) patients were from high risk group.

Table 6: Maternal complications among study groups in intrapartum and postpartum period.

\begin{tabular}{|c|c|c|}
\hline Maternal complications & $\begin{array}{l}\text { Low risk } \\
\text { group } \\
(\mathrm{n}=56)\end{array}$ & $\begin{array}{l}\text { High risk } \\
\text { group } \\
(n=19)\end{array}$ \\
\hline & $\begin{array}{l}\text { No. of } \\
\text { cases }(\%)\end{array}$ & $\begin{array}{l}\text { No. of } \\
\text { cases }(\%)\end{array}$ \\
\hline Post-partum hemorrhage & $3(5.36)$ & $0(0.00)$ \\
\hline Acute pulmonary edema & $1(1.78)$ & $2(10.53)$ \\
\hline CCF & $2(3.58)$ & $3(15.79)$ \\
\hline Acute febrile illness & $1(1.78)$ & $0(0.00)$ \\
\hline Acute hypoxia & $2(3.58)$ & $1(5.27)$ \\
\hline Anemia & $2(3.58)$ & $2(10.53)$ \\
\hline Atrial fibrillation & $1(1.78)$ & $0(0.00)$ \\
\hline Left ventricular failure & $1(1.78)$ & $1(5.27)$ \\
\hline Wound gape & $1(1.78)$ & $0(0.00)$ \\
\hline $\begin{array}{l}\text { Lower respiratory tract } \\
\text { infection }\end{array}$ & $0(0.00)$ & $1(5.27)$ \\
\hline Sepsis & $0(0.00)$ & $1(5.27)$ \\
\hline $\begin{array}{l}\text { Supraventricular } \\
\text { tachycardia }\end{array}$ & $0(0.00)$ & $1(5.27)$ \\
\hline
\end{tabular}

On application chi square test, high risk pregnancy were significantly associated with ICU admission after delivery (Pearson Chi-Square 24.975 and $\mathrm{p} \mathrm{0.00001).}$ There were 5 deaths reported in patients with heart disease during the study period. All of them belonged to the high risk group. The cause of death was congestive cardiac failure.( TABLE 6). A major risk factor found for these deaths was inadequate optimization of the patient in antenatal period and delayed referral to our hospital.

Table 7: Details of maternal deaths.

\begin{tabular}{|c|c|c|c|c|c|c|}
\hline Age & Parity & $\begin{array}{l}\text { Gestational } \\
\text { age }\end{array}$ & Cardiac lesion & $\begin{array}{l}\text { NYHA } \\
\text { Grade }\end{array}$ & LVEF & Cause of death \\
\hline 23 & 2 & 35 & $\begin{array}{l}\text { Dilated cardiomyopathy ( post viral } \\
\text { myocarditis), pericardial effusion, } \\
\text { LV diastolic dysfunction } \\
\text { (restrictive type) }\end{array}$ & 4 & 30 & Congestive cardiac failure \\
\hline 30 & 5 & 27 & Peripartum dilated cardiomyopathy & 4 & 30 & Acute left ventricular failure. \\
\hline 23 & 1 & 36 & $\begin{array}{l}\text { Bidirectional ASD, severe PAH, } \\
\text { severe pulmonary stenosis, } \\
\text { Eisenmenger syndrome }\end{array}$ & 3 & 55 & $\begin{array}{l}\text { Cardiogenic shock with } \\
\text { acute left ventricular failure. }\end{array}$ \\
\hline 27 & 1 & 32 & RHD, prosthetic valve thrombosis & 4 & 25 & $\begin{array}{l}\text { Cardiogenic shock } \\
\text { secondary to prosthetic } \\
\text { valve thrombosis. }\end{array}$ \\
\hline 21 & 1 & 36 & $\begin{array}{l}\text { RVHD, severe MS, severe PAH, } \\
\text { mild TR, mild MR, moderate AR }\end{array}$ & 3 & 55 & $\begin{array}{l}\text { Atrial fibrillation and } \\
\text { pulmonary edema, } \\
\text { succumbed to cardiogenic } \\
\text { shock secondaryto critical } \\
\text { MS and left atrial thrombus. }\end{array}$ \\
\hline
\end{tabular}


Table 8: Perinatal outcome among study groups.

\begin{tabular}{|llll|}
\hline $\begin{array}{l}\text { Perinatal } \\
\text { complication }\end{array}$ & $\begin{array}{l}\text { Low risk } \\
\text { group } \\
\text { No. of } \\
\text { cases (\%) }\end{array}$ & $\begin{array}{l}\text { High risk } \\
\text { group } \\
\text { No. of cases } \\
(\%)\end{array}$ & $\begin{array}{l}\text { Total } \\
\text { cases } \\
\text { No. of cases } \\
(\%)\end{array}$ \\
\hline Preterm & $11(19.64)$ & $10(52.63)$ & $21(28.3)$ \\
\hline IUGR & $11(19.64)$ & $12(63.16)$ & $23(31.08)$ \\
\hline $\begin{array}{l}\text { Still } \\
\text { birth/IUD }\end{array}$ & $0(0.00)$ & $3(15.7)$ & $3(4.05)$ \\
\hline $\begin{array}{l}\text { Low birth } \\
\text { weight } \\
\text { (<2500g) }\end{array}$ & $20(35.71)$ & $14(73.68)$ & $34(45.9)$ \\
\hline $\begin{array}{l}\text { Very low } \\
\text { birth weight } \\
\text { (<1500g) }\end{array}$ & $0(0.00)$ & $2(10.5)$ & $2(2.70)$ \\
\hline $\begin{array}{l}\text { NICU } \\
\text { admission }\end{array}$ & $8(14.29)$ & $8(42.11)$ & $16(21.6)$ \\
\hline $\begin{array}{l}\text { Congenital } \\
\text { heart disease }\end{array}$ & $1(1.79)$ & $3(15.79)$ & $4(5.4)$ \\
\hline $\begin{array}{l}\text { Another } \\
\text { congenital } \\
\text { anomaly }\end{array}$ & $0(0.00)$ & $0(0.00)$ & $0(0.00)$ \\
\hline $\begin{array}{l}\text { Need of } \\
\text { resuscitation }\end{array}$ & $3(5.36)$ & $5(26.32)$ & $8(10.8)$ \\
\hline $\begin{array}{l}\text { APGAR } \\
\text { at 5 minutes }\end{array}$ & $2(3.57)$ & $0(0.00)$ & $2(2.7)$ \\
\hline
\end{tabular}

When perinatal outcome is studied according to low and high-risk groups, it was observed that low birth weight babies were more common in high risk $(73.8 \%)$ than low risk $(35.7 \%)$ patients. This was also found to be statistically significant. Intrauterine growth restriction was seen in $19.6 \%$ neonates of low risk group and $63.1 \%$ neonates of high risk group which was again statistically significant. These neonatal complications were not exclusive of each other. (Table 7).

\section{DISCUSSION}

In this study, we observed a whole spectrum of cardiac conditions and it was noted that many symptoms and signs of normal pregnancy mimic those indicative of heart disease, thus making clinical diagnosis difficult. 75 pregnant women with congenital or acquired cardiac lesion or those with cardiac arrhythmias registered or referred to the hospital were analysed. Those pregnant women who did not give consent to participate in the study, had voluntary Medical termination of pregnancy or spontaneously aborted before 20 weeks were excluded from the study. When compared obstetric characteristics with other studies, the mean age of the patient was 24.07 years while 26.3 years was reported by Ekachai et al. ${ }^{8}$ Mean gestational age was $38.1 \pm 3.9$ weeks which was comparable to the study done by Kovavisarach et al i.e. $37.7 \pm 2.4$.

Rheumatic heart diseases constituted $64 \%$ of cardiac disorders in patients delivering in our hospital. RVHD accounted for $88 \%$ of cardiac disorders in pregnant women in the study by Bhatla et al and Asghar et al in Pakistan. ${ }^{9,10}$ It accounted for $66 \%$ in a study done by Avila WS et al. ${ }^{11}$ The rate of RVHD was falling slowly since the last decade due to better awareness of antenatal surveillance through media and availability of antibiotics. $^{12}$ This demonstrates the importance of the treatment of rheumatic heart disease in a developing country. In our study among patients with RVHD and pregnancy, mitral stenosis is the most common lesion present in $30 \%$ of patients. ${ }^{13}$ Mitral valve was affected alone or in combination in most of the cases. In mitral stenosis, the increase in cardiac output is limited by the amount of blood that can flow through the narrowed valve during diastole. The pregnancy induced increase in the maternal heart rate shortens the diastole, reducing left ventricular filling. In a few instances, this can lead to reduced cardiac output, increased left atrial pressure and cardiac failure. Often the deterioration is acute, typically due to an arrhythmia, usually atrial fibrillation secondary to the stretch of the left atrium. About $40 \%$ of women with mitral stenosis, experienced some symptomatic decline in cardiac function during pregnancy. ${ }^{14}$ The ratio of RVHD to CHD in our study is 2:1 which is comparable to that of developing countries.

We encountered $36 \%$ of congenital heart diseases compared to $19.1 \%$ reported by a study done by Asghar et al, while it is $76 \%$ in a study done by Stangl et al in a developed country. ${ }^{14,15}$ The predominant congenital cardiac lesion was an atrial septal defect present in $44 \%$ of patients, while according to a study done by Madazli et al it is $33.3 \%$. $^{16}$

We classified our patients as per WHO classification based on the severity of the cardiac lesion, the maximum number of patients were in WHO class II (37.3\%) and minimum in WHO class III $(16 \%)$. The WHO class I was less as they are asymptomatic, hence, remain undiagnosed. Being a tertiary care center, $22.67 \%$ of our patients belonged to WHO Class IV.

We divided our study group broadly into 2 groups- High risk and low risk based on NYHA criteria wherein NYHA I + NYHA II belonged to low risk group and NYHA III + NYHA IV belonged to high risk group. Various complications were found in patients with heart disease during their antenatal follow up. These complications should be detected at the earliest stage and treated accordingly to get a better outcome of pregnancy. The most common complication found was PROM (41.3\%) followed by IUGR (30.67\%). Rhythm disorders may cause significant hemodynamic compromise to both mother and fetus and may impair the outcome.

In our study, only 1 patient died in the antenatal period. She was a 27 years old, primigravida, case of RVHD with mitral prosthetic valve replacement done in 2011. She was on an anticoagulant (T. warfarin) since 2011. She was unregistered and unimmunized and presented at the 
seventh month of gestation with prosthetic valve thrombosis and acute left ventricular failure. 2D ECHO showed choked mitral valve prosthesis, moderate TR, severe $\mathrm{PAH}$ and severe LV dysfunction (ejection fraction=25\%). She succumbed due to cardiogenic shock secondary to prosthetic valve thrombosis.

When we studied the mode of delivery between the low risk and high-risk groups, it was found that the most common mode of delivery is vaginal delivery and there was a statistically significant association between high risk group and the need for cesarean section. The cesarean section rate was $14.2 \%$ in the low risk group and $50 \%$ in high risk group. The comparison with other studies has been shown in the table below with respect to the mode of delivery.

Table 9: Comparison of mode of delivery among various studies.

\begin{tabular}{|c|c|c|c|}
\hline Study & Vaginal & LSCS & $\begin{array}{l}\text { Forceps/ } \\
\text { ventouse }\end{array}$ \\
\hline Our study & $64 \%$ & $23 \%$ & $13 \%$ \\
\hline Asghar et al $^{10}$ & $8.5 \%$ & $8.5 \%$ & $82.9 \%$ \\
\hline Devabhaktuni et al ${ }^{17}$ & $53.2 \%$ & $37.6 \%$ & \\
\hline
\end{tabular}

$74.6 \%$ of all patients went into spontaneous labour of which $12.5 \%$ patients underwent emergency LSCS.16\% of patients were in induced labour of which $33 \%$ patients underwent LSCS. There was a significant association between onset of labour (spontaneous/induced) and need of emergency LSCS, irrespective of risk category. When we consider overall modes of delivery without classifying them into different groups, vaginal delivery is the most common mode of delivery accounting for $64 \%$ which can be compared to a study done by Verena et al which is $45 \% .^{15}$ LSCS were done in $23 \%$ while $13 \%$ of deliveries were done by either forceps or ventouse. Epidural anaesthesia, being the safer mode of anaesthesia in heart disease, was given in $53 \%$ of the cases.

In our study 5 out of 75 cases developed congestive cardiac failure $(6.6 \%)$ which is very low when compared to $12.3 \%$ and $38 \%$ in studies done by Avila et al and Hameed et al respectively. ${ }^{11,17}$ It was encountered in two cases in low risk group $(3.58 \%)$ and three cases in highrisk group $(6.6 \%)$. During the first $24-72$ hours, the postdelivery significant fluid shift can lead to congestive cardiac failure. So vital signs and fluid balance charts should be carefully maintained in the immediate postpartum period.

The most common postpartum complication was congestive cardiac failure. Being a tertiary care centre and one the largest referral centre in central India, the incidence of complications among patients of heart disease at our institute cannot be extrapolated to the general population. ICU admission was required for $10.7 \%$ of low patients and $68.1 \%$ of high-risk patients. Infective endocarditis was not seen in a single patient in our study due to the routine use of antibiotics. It was seen in $0.5 \%$ cases in the study by Avila et al. ${ }^{11}$

In perinatal outcomes, prematurity accounted for $19.64 \%$ in low risk group and $52.63 \%$ in high risk group. This association between the severity of the disease and prematurity was found to be statistically significant. According to a study done by Kovavisarach et al at Rajavithi hospital, preterm delivery is seen in $5 \%$ of cases (NYHA I, II) and in $45 \%$ cases (NYHA III; IV). ${ }^{8}$

The potential for successful pregnancy outcome is determined by the maternal functional status prepregnancy. Most of our patients (74.67\%) were in a good functional state (NYHA class I and II). In a study done by Madazli et al, it was $92 \%$ and similar percentages for NYHA classes I and II have been reported in most of the other series. ${ }^{9,18,19}$ Poor NYHA class or cyanosis was reported to be a predictive factor for perinatal mortality and morbidity. ${ }^{20,21}$

Maternal morbidity was significantly higher in our highrisk group. This finding supports previous studies, which have shown that cardiovascular maternal morbidity correlates with the maternal functional status. ${ }^{20,21,22}$ In our study there were 2 patients with Eisenmenger syndrome who were managed effectively due to a multidisciplinary approach since the early months of pregnancy. They had no complications during the intrapartumand postpartum period. A 23-year-old primigravida at 36 weeks of gestation with Eisenmenger syndrome, severe PAH and severe Pulmonary stenosis underwent emergency LSCS under epidural for cephalopelvic disproportion. Immediately post-operatively, she developed acute hypoxia and was shifted to ICU where she was stabilized. She recovered and was shifted to ward. On postoperative day 7 , she suddenly collapsed and become unconscious and died due to cardiogenic shock with acute left ventricular failure. Eisenmenger syndrome involves pulmonary vascular obstructive disease resulting from a pre-existing left-to-right shunt. Over time, pulmonary pressures rise to systemic levels changing the shunt flow to right-to-left. Most complications during pregnancy occur at term and during the first postpartum weeks, as it did in our patient.

Spontaneous abortion, intrauterine growth restriction, and preterm labour are frequent. Perinatal mortality is due mainly to prematurity. Maternal and neonatal mortality rates are high in patients with pulmonary hypertension. A 1998 review of 125 pregnancies found the maternal mortality rate to be $30 \%$ in those with primary pulmonary hypertension, $36 \%$ in those with Eisenmenger syndrome, and $56 \%$ in those with secondary vascular pulmonary hypertension. The overall neonatal mortality rate was $12 \% .^{23}$ Due to high maternal mortality, termination of pregnancy is indicated preferably in the first trimester in cases with Eisenmenger syndrome, pulmonary arterial HTN, severe Left heart obstructive lesions and Marfan's syndrome with aortic root diameter $4 \mathrm{~cm}^{2} .{ }^{24}$ Termination 
of pregnancy would be needed in major congenital fetal anomalies. With the appropriate management and multidisciplinary teamwork, except for the minority of patients with severe disease requiring medical or surgical therapy before pregnancy, and for those with lesions where pregnancy is contraindicated, pregnancy usually has a successful outcome in patients with heart disease.

\section{CONCLUSION}

Heart disease in pregnancy is an important cause of maternal mortality in India. Mortality is high if heart disease is complicated with infective endocarditis in pregnancy. Therefore, every step should be taken to prevent this complication. Low birth weight and pre-term birth are the major neonatal complications in heart disease in pregnancy. The perinatal outcome is more dependent on the severity of symptoms during pregnancy rather than the duration and type of heart disease. These patients should be registered early in pregnancy at a tertiary care centre. Multidisciplinary evaluation is necessary. Preventable complications like anemia and infective endocarditis should be actively managed in antenatal period. In labour, 2nd stage of labour should be cut short and active management of 3rd stage of labour should be done. Judicious use of diuretics is essential to prevent congestive cardiac failure. Antibiotics should be continued in postnatal period. An effective contraceptive should be advised to all patients with heart disease. Suboptimal optimization of the heart condition in the antenatal period, delay in seeking medical care and delay in referral were the major risk factor for maternal mortality in our patients.

\section{Funding: No funding sources}

Conflict of interest: None declared

Ethical approval: The study was approved by the Institutional Ethics Committee

\section{REFERENCES}

1. Rhodes YA, Preive AM. Assesment and evaluation of women with cardiac disease during pregnancy. J perinat Neonatal Nurs. 2006;20:295-302.

2. Surge D, Blake S, McDonald D. Pregnancy complicated by maternal heart disease at the National Maternity Hospital, Dublin. Int J Gynaecol Obstet. 1978;8:20-9.

3. Faul P, Dornan J, Lamki H. Pregnancy complicated by maternal heart disease: a review of 519 women. $\mathrm{Br} \mathrm{J}$ Obstet Gynaecol. 1998;95:861-7.

4. Swiet M. Heart disease in pregnancy. In: Swiet M, editor. Medical disorders in obstetric practice. Oxford: Blackwell. 1984:483-504.

5. Konar H. Medical disorders in pregnancy. Who should see the woman? J Indian Med Assoc. 2004;102:131.
6. DeSweit M. Cardiac disease. In: Lewis G, Drife J, editors. Why mothers die 1997-1999. The confidential enquiries into maternal deaths in the United Kingdom. London: RCOG Press. 2001:153-64.

7. Gelson E, Mank J, Gatzoulis M. Cardiac disease in pregnancy. Obstet Gynaecol. 2007;9:83-7.

8. Kovavisarach E, Nualplot P. Outcome of pregnancy among parturients complicated with heart disease in Rajavithi Hospital. J Med Assoc Thai. 2007;90(11):2253-9.

9. Bhatla NS, Behera G. Cardiac disease in pregnancy. Int J Gynaecol Obstet. 2003;82:153-9.

10. Asghar F, Kokab H. Evaluation and outcome of pregnancy complicated by heart disease. J Pak Med Assoc. 2005;55(10):416-9.

11. Avila WS, Rossi EG, Ramires JA. Pregnancy in patients with heart disease: experience with 1,000 cases. Clin Cardiol. 2003;26:135-42.

12. Gupta A, Lokhandwala YY, Satoskar PR. Balloon mitral valvotomy in pregnancy. Maternal and fetal outcome. J Am Coll Surg. 1998;187:409-15.

13. Desai DR, Adanlawo M, Naidoo DP. Mitral stenosis in pregnancy: A four year experience at King Edward Viii Hospital, Durban, South Africa. Br J Obstet Gynaecol. 2000;107:953-958.

14. Silversides CK, Colman JM, Sermer M. Cardiac risk in pregnant women with rheumatic mitral stenosis. Am J Cardiol. 2003;91(11):1382-5.

15. Stangl V, Schad J, Gossing G. Maternal heart disease and pregnancy outcome: a single-center experience. Eur J Heart Fail. 2010:18760667.

16. Madazli R, Sal V. Pregnancy outcomes in women with heart disease. Arch Gynecol Obstet. 2010;281:29-34.

17. Hameed A Karralp IS, Tummula PP et al (2001) The effects of valvular heart disease on maternal and fetal outcome of pregnancy. J Am Con Cardiot 37:893-899

18. Siu SC, Sermer M, Colman JM, et al. Prospective multicentre study of pregnancy outcomes in women with heart disease. Circulation 2001:104:515-521

19. Hady ES, Shamy M, Rifai AA. Maternal and perinatal outcome of pregnancies complicated by cardiac disease. Int J Gynaecol Obstet. 2005;90:21- 5.

20. Sawhney H. Aggarwal N, Suri V. Maternal and perinatal outcome in rheumatic heart disease. Int $\mathrm{J}$ Gynaecol Obstet. 2003;80:9-14.

21. Keepanasseril A, Pillai AA, Yavanasuriya J, Raj A, Satheesh S, Kundra P. Outcome of pregnancies in women with pulmonary hypertension: a single-center experience from South India. BJOG Int $\mathbf{J}$ Obstet Gynaecol. 2019;126:43-9.

22. Sermer M, Colman J, Siu S. Pregnancy complicated by heart disease: a review of Canadian experience.J Obstet Gynaecol. 2003;23:540-4.

23. Weiss BM, Zemp L, Seifert B, Hess O. Outcome of pulmonary vascular disease in pregnancy: a systematic overview from 1978 through 1996. J Am Coll Cardiol. 1998;31:16501657.

24. Uebing A, Steer PJ, Yentis SM. Pregnancy and congenital heart disease. BMJ. 2006;7:1326.

Cite this article as: Goel K, Tambe SG. A study to evaluate pregnancy with maternal heart disease: a prospective observational study at a tertiary care centre in India. Int J Reprod Contracept Obstet Gynecol 2021;10:1637-43. 